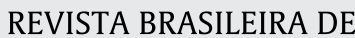

\section{Genetic study in Aedes (Stegomyia) aegypti (Linnaeus, 1762) from Londrina (Paraná State, Brazil): an approach to population structure and pyrethroid resistance ${ }^{a}$}

\author{
Thayná Bisson Ferraz Lopes ${ }^{1}$, Tafarel Ribeiro Amaro ${ }^{1}$, Bianca Piraccini Silva ${ }^{1}$, \\ João Antonio Cyrino Zequi ${ }^{1}$ (D), Gislayne Trindade Vilas-Bôas ${ }^{1}$, \\ Mario Antonio Navarro da Silva ${ }^{2}$, Beatriz Trindade Vilas-Boas ${ }^{3}$, Renata da Rosa ${ }^{1 *}$ \\ ${ }^{1}$ Universidade Estadual de Londrina, Londrina, PR, Brasil. \\ 2Universidade Federal do Paraná, Curitiba, PR, Brasil. \\ ${ }^{3}$ Colégio Universitário, Londrina, $P R$, Brasil.
}

\section{A R T I C L E I N F O}

\section{Article history:}

Received 21 August 2020

Accepted 02 January 2021

Available online 01 March 2021

Associate Editor: Maria Sallum

\section{Keywords:}

allele-specific PCR

knockdown resistance

mtDNA

ND4 gene

voltage-gated sodium channel

\begin{abstract}
A B S T R A C T
Londrina is the fourth most populous city in southern Brazil. Its subtropical weather with rain in all seasons, as well as its high population density, make the city perfect for the Aedes aegypti(Linnaeus, 1762) life cycle. Over the last few years, Londrina presented high infestation indexes and was one of the cities with the most reported cases of dengue. Uncontrolled use of synthetic insecticides may influence the mosquito's genetic composition. In this paper, we studied mitochondrial DNA and $k d r$ mutations in Aedes aegypti. The analysis of the ND4 gene in 330 specimens showed the presence of 27 haplotypes. The pyrethroid resistance alleles $(k d r)$ evaluated are present in the collected populations, with a 50\% frequency of the Val1016Ile and 48\% of the Phe1534Cys mutations. Such analysis of the mutations in the populations collected at the State University of Londrina's campus - a microenvironment that differs from the rest of the city - showed frequencies of $57 \%$ and $62 \%$, respectively. The low gene flow observed, $\mathrm{Nm}=0.11$ and $\mathrm{Nm}=0.10$, along with the elevated differentiation, $\mathrm{F}_{\mathrm{st}}=0.19$ and $\mathrm{F}_{\mathrm{st}}=0.18$, among populations suggest an influence of genetic drift. The strong presence of resistance alleles kdr in the city is evident, which demonstrates that even with the interruption of the use of pyrethroids by the National Dengue Control Program, resistance may be maintained due to domestic use. Thus, the results have shown the need for genetic monitoring, alongside other entomological surveillance monitoring tools, to create strategies of mosquito control.
\end{abstract}

\section{Introduction}

Dengue is a viral infection (DENV) transmitted by the Aedes aegypti (Linnaeus, 1762) mosquito and can be asymptomatic, mild, or severe (WHO, 2018). Since 1846, dengue has been reported in Brazil, although only in 1986 did it become epidemiologically important after an epidemic in Rio de Janeiro state, becoming endemic in Brazil (Martins et al., 2008).

According to the Pan American Health Organization (PAHO), in the last ten years, over 11 million dengue cases have been registered in Brazil. In 2019, between Epidemiological Weeks (SE) 1 and 52 (12/30/2018 to $12 / 30 / 2019$ ), more than $1,500,000$ cases were registered in the country, and 49,509 cases were registered in the South region alone. Paraná State recorded the highest number of cases in the South region

\footnotetext{
* Corresponding author:

E-mail: renata-darosa@uel.br (R. da Rosa)
}

(45,482 cases), with an incidence of 397.8 cases / 100,000 inhabitants and 31 deaths (Ministério da Saúde, 2020). In the present year of 2020, between SE 1 and 26 (12/29/2019 to 6/27/2020), the South region has already registered 276,873 cases, of which 260,307 cases (with an indication of 2,276.6 cases / 100 thousand hab) are in Paraná State.

In Brazil, control and monitoring strategies began several years ago in a traditional way by making use of the Infestation Index Rapid Survey for Ae. aegypti (LIRAa), elimination of habitats, either by health agents or by the population through educational activities, growth regulators and chemical insecticides (when the other types of measurement are not possible to be performed) (Araújo et al., 2015; Zara et al., 2016). Currently, these traditional methods of breeding site monitoring are the most efficient strategies available in the surveillance of Ae. aegypti. Pyrethroid (PY) insecticides have been used to control mosquitoes since 2000 as an alternative to organophosphate malathion,

${ }^{a}$ HW: Hardy-Weinberg equilibrium; Kdr: Knockdown resistance gene; LIRAa: Infestation Index Rapid Survey for Ae. aegypti; NaV: Voltage-gated sodium channel; PY: Pyrethroids. 
and the first resistance report occurred a few years later (Lima et al., 2003; Da-Cunha et al., 2005). Currently, synthetic PY is the most used control mechanism by the population because it is easy to acquire in supermarkets and practical use inside homes to control Ae. aegypti adults (Saavedra-Rodriguez et al., 2018). However, the use of these compounds by government campaigns and uncontrolled domestic application represents a major collective health problem, as it leads to the selection of highly resistant populations (Vontas et al., 2012).

Specifically, in Londrina (Paraná, Brazil), chemical control with adulticides, the focus of this paper, is carried out by the city following the recommendations in the National Dengue Control Program (PNCD) since it receives inputs from the federal government. In the last 10 years, malathion was the main method of adult control in Londrina. In 2020, Cielo has been used, which is a mixture of neonicotinoid and pyrethroid as recommended in the PNCD use supplies. Even in the last decade, the non-use of pyrethroids by public agencies, the population has free access to pyrethroids, being used frequently in the home preferred site for Ae. aegypti, in the form of spray or other liquid vapors or in tablets.

The resistance to PY recurs in most regions where Ae. aegypti is already established (WHO, 2018). Studies have demonstrated that mutations in the voltage-gated sodium channel $\left(\mathrm{Na}_{\mathrm{v}}\right)$ often play a significant role in PY resistance. $\mathrm{Na}_{\mathrm{v}}$ are voltage-gated sodium channel transmembrane proteins composed of four homologous domains (I-IV), each with six hydrophobic segments (S1-S6), present in neuronal axons (Catterall, 2000). $\mathrm{Na}_{\mathrm{v}}$ mutations, which reduce the connection to PY, are known as knockdown resistance $(k d r)$ because of insects' immediate loss of coordination due to exposure to insecticides and their subsequent recovery.

Eleven $k d r$ mutations in $\mathrm{Na}_{\mathrm{v}}$ have been observed in several Ae. aegypti populations $\left(\mathrm{AaNa}_{\mathrm{v}}\right)$, and in its majority, with a certain degree of PY resistance (Saavedra-Rodriguez et al., 2018). In Brazil, some mutations have been mentioned, with Phe1534Cys being one of the five proven to be related to PY sensitivity loss in cooccurrence to the Val1016Ile mutation (Lima et al., 2011; Linss et al., 2014). The latter mutation is a result of the substitution of a valine for an isoleucine (GTA-ATA), while Phe1534Cys results in the substitution of a phenylalanine for a cysteine (TTC-TGC) and are in the $\mathrm{Na}_{\mathrm{v}}$ IIS6 and IIIS6 regions, respectively (Linss et al., 2014).

Insecticide and the presence of mutation susceptibility monitoring is an important strategy in increasing the knowledge of resistance mechanisms (Braga and Valle, 2007; Saavedra-Rodriguez et al., 2018). The interaction with Ae. aegypti genetic diversity analysis might be applied with the objective of knowing the structure of the populations to comprehend their dynamics, providing data that might lead to new control measures.

Characterizing the genetic structure and gene flow in insects that are vectors to pathogens is of utmost importance in aiding control programs, producing vaccines and maintaining public health. Mitochondrial DNA (mtDNA) is a target of Ae. aegypti genetic population studies in different locations, the mitochondrial gene ND4, which encodes subunit 4 of the NADH dehydrogenase enzyme, which is important in the electron transport chain. In Brazil, some populational studies have already been conducted (Bracco et al., 2007; Lima Júnior and Scarpassa, 2009), including some populations from the state of Paraná (Bona et al., 2012) and even the city of Londrina (Twerdochlib et al., 2012). This type of analysis may provide data for characterizing the populational structure, as well as working as a basis for new Ae. aegypti control methodologies to be applied.

The integration of different vector control strategies, considering both the available alternatives and the specific regional characteristics, seems to be a feasible mechanism to reduce mosquito infestation and arbovirus incidence transmitted by them, since a unique solution for
Ae. aegypti control in Brazil is absent (Zara et al., 2016). In addition, an assessment of mutations related to resistance to pyrethroids can highlight the results of the indiscriminate use of household insecticides. Thus, the objective of the present study was to identify the genetic variety of Ae. aegypti in Londrina by using the ND4 gene and, evaluate the presence of $k d r$ resistance mutations in the city.

\section{Material and Methods}

\section{Sampling}

Eleven locations were chosen in five different regions of the city of Londrina (North, South, East, West and Central) to collect eggs using georeferenced oviposition traps (Fig. 1, Table S1): (1) Conjunto Maria Cecília (North region); (2) Conjunto Aquiles Stenghel (North region); (3) União da Vitória (South region); (4) Parque das Indústrias (South region); (5) Armindo Guazzi (East region); (6) Vila Ricardo (East region); (7) Jardim Bandeirantes (West region); (8) Jardim Leonor (West region); (9) Vila Casoni (Central region); (10) Centro Social Urbano (Central region); (11) Vila Brasil (Central region). In addition to these locations, State University of Londrina (UEL)'s campus was also selected for presenting different characteristics than the rest of the city, being a microenvironment itself. In UEL, three locations were selected for installing the traps: Centro de Ciências Biológicas (CCB), Biblioteca Central (BC) and Centro de Estudos Sociais Aplicados (CESA) (Fig. 1). The distances among them are similar (close to $500 \mathrm{~m}$ ), with distinct anthropic influences. CCB and BC are surrounded by buildings with heavy human flow, while CESA - also with heavy human flow - is the threshold between campus and forest fragment environments due to its proximity to the University's grove. The sampling was authorized by Londrina's Health Secretary and ICMBio (number 27414-1) and took place between November and December of 2017.

Aedes aegypti eggs were obtained according to Depoli et al. (2016). Black $500 \mathrm{~mL}$ plastic vases were used as traps for ovoposition, containing $300 \mathrm{~mL}$ of a mosquito attracting mix - consisting of $250 \mathrm{~mL}$ distilled water and $50 \mathrm{~mL}$ of grass infusion containing $50 \mathrm{~mL}$ of the attracting infusion of mosquitoes (34 g of Colonião grass [Megathyrsus maximus (Jacq.)] in $8 \mathrm{~L}$ of water, 5 days fermented in a plastic bucket at room temperature) into $250 \mathrm{~mL}$ of distilled water. Inside the traps, a $15 \times 3 \mathrm{~cm}$ band of Duratree. Five traps were placed in each site and they remained there for five days. The collected eggs were submerged in water at the General and Medic Entomology laboratory for hatching, and larvae were kept in controlled conditions $\left(25 \pm 2^{\circ} \mathrm{C}\right.$, humidity $80 \pm 10 \%$ e $14: 10$ hours photoperiod) and fed with $1 \mathrm{~mm}$ particle fish food (Tetramix, autoclaved) until adults. To identify Ae. aegypti individuals, Consoli and Oliveira (1994), Forattini (2002) and WRBU (2018) identification keys were used, in addition to Opton stereoscopic microscope (40X) CH30LF100, and thirty adults from each location were selected after identification. The mosquitoes were individually stored in absolute ethanol at $-20^{\circ} \mathrm{C}$ for further analysis.

\section{Mitochondrial ND4 gene amplification}

Total DNA extraction was performed according to Aguirre-Obando et al. (2015). Two hundred eighty (twenty from each site) were selected for evaluating the ND4 gene. Two primers were used for amplification: an ND4F primer: 5'-ATT GCC TAA GGC TCA TGT AG-3' and a reverse ND4R primer: 5'-TCG GCT TAG TAG TAG ATTC-3' (Costa-da-Silva et al., 2005). The PCRs and sequencing followed Twerdochlib et al. (2012). The obtained sequence alignments were made using BioEdit Software version 7.0.5 (Hall, 2005) using the ClustaIW tool (Thompson et al., 1994). 


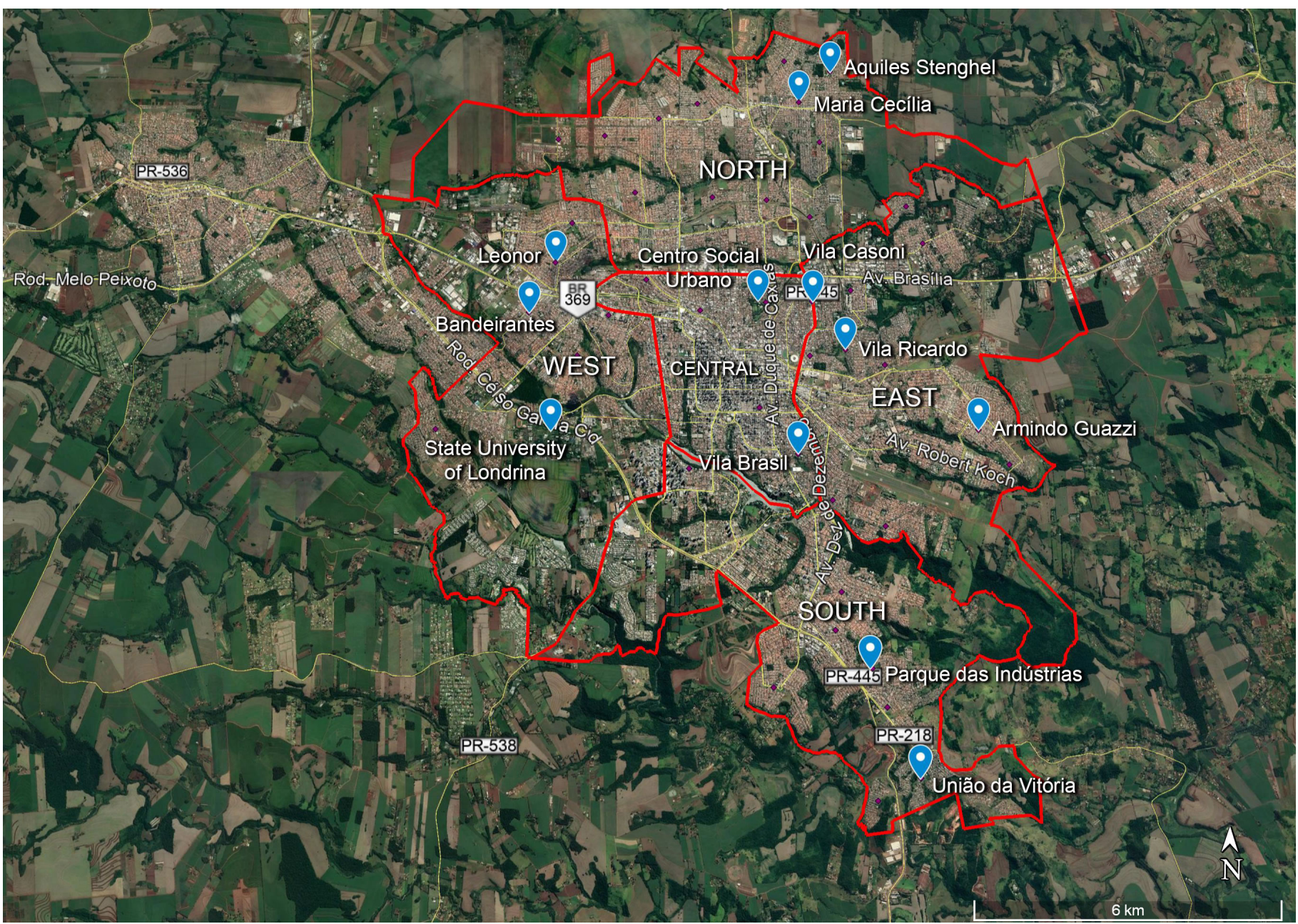

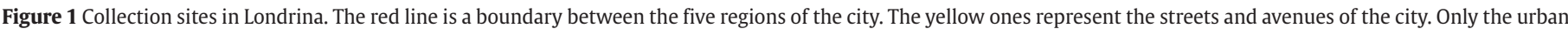
area was evaluated in the study.

The acquired sequences were compared to those available in GenBank using the TBlastx tool to confirm the amplified fragment. The relation between the haplotypes was inferred by constructing a haplotype network created with the help of Network Software (Bandelt et al., 1999). The genetic diversity and neutrality tests (Tajima's D and Fu's Fs) were calculated using DnaSP Software version 6 (Rozas et al., 2017). The analysis of molecular variance (AMOVA) was performed using the software Arlequin version 3.5 (Excoffier and Lischer, 2010). The population structure was determined using Wright's fixation index $\left(\mathrm{F}_{\mathrm{ST}}\right.$, Wright, 1921), and the genetic flow (Nm) was also obtained using Arlequin 3.5 (Excoffier and Lischer, 2010).

\section{Genotyping of the Nav 1016 and 1534 sites}

For the Val1016Ile mutation, the following primers were used: 1016Val 5'-GCG GGC AGG GCG GCG GGG GCG GGG CCA CAA ATT GTT TCC CAC CCG CAC CGG-3', 1016Ile 5'-GCG GGC ACA AAT TGT TTC CCA CCC GCA CTG A-3' and the same reverse primer for both: 5'-GGA TGA ACC GAA ATT GGA CAA AAG C-3'. The amplification conditions occurred following Saavedra Rodriguez et al. (2007) and Martins et al. (2009). For the Phe1534Cys mutation, the reverse primer 5'-TCT GCT CGT TGA AGT TGT CGA T-3' was used for both alleles, and the allele-specific forward

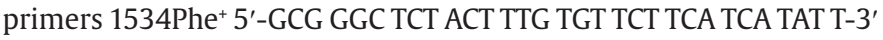
e 1534Cyskdr 5'-GCG GGC AGG GCG GCG GGG GCG GGG CCT CTA CTT
TGT GTT CTT CAT CAT GTG-3'. The amplification conditions were as described by Harris et al. (2010). To verify the amplified alleles, a 10\% polyacrylamide gel was prepared and stained with SYBR ${ }^{\circ}$ Safe (Kasvi:6x). Thirty samples from each location were genotyped for both mutations. By analyzing the amplicons, the genotype and allele frequencies were calculated, and the Hardy-Weinberg (HW) equilibrium hypothesis test was performed. The analyses were conducted in two different ways: first, each region of both the city and the University campus was considered and individually analyzed. Second, all of Londrina's sampling sites were grouped, as well as the University's, and analyzed as a group.

\section{Results}

\section{Populational structure analysis}

The amplified product of the ND4 gene for Londrina's samples was 339 bp with the presence of 13 polymorphic sites and 326 monomorphic sites (Table 1). The amplified fragment analysis resulted in 17 haplotypes (Fig. 2). The most frequent haplotypes were $\mathrm{H} 5$ and H11. The haplotypes were defined by four transitions $\mathrm{G} \leftrightarrow \mathrm{A}$ (sites 104, 143, 321 and 325) and nine transversions $A \leftrightarrow T$ (sites 93 and 321), $T \leftrightarrow G$ (sites 111, 155, and 286), $C \leftrightarrow A$ (sites 230 and 300) and $C \leftrightarrow G$ (sites 311 and 317). The average nucleotide composition was $41.1 \%$ adenine, $29.4 \%$ thymine, $21.5 \%$ cytosine and $8.0 \%$ guanine. 
The haplotypic diversity (Hd) was $0.862 \pm 0,011$ (average \pm standard deviation, $\mathrm{n}=220$ ). Nucleotide diversity $(\pi)$ was $0.0055 \pm 0.0003$, with 1.876 nucleotide differences on average. Some haplotypes were rare, such as H1-H2, H7-H10 and H15-16. Except for haplotypes H4, H5, $\mathrm{H} 11$ and H12, all the others are from exclusive regions, showing each region's particularities (Fig. 2 ).

Neutrality test results were not significant according to neutral mutation model assumptions ( $\mathrm{p}>0.10$, Tajima's D -0.8799, Fu's Fs -4.8888 ). Gene flow was $\mathrm{Nm}=0.11$. The analysis of molecular variance (AMOVA, $\left.\mathrm{F}_{\mathrm{st}}=0.19, \mathrm{p}<0.05\right)$ showed genetic differentiation.
For UEL campus ND4, the mitochondrial amplified gene product was also 339 bp, however, with 12 polymorphic sites and 327 monomorphic sites (Table 2). The amplified fragment analysis resulted in 10 haplotypes (H1-H10). The most frequent were H24 and H26 (Fig. 2). The haplotypes were defined by four transitions: $G \leftrightarrow A$ (site 79) and $T \leftrightarrow C$ (sites 118, 132 and 134) and eight transversions: $A \leftrightarrow T$ (sites 114, 279 and 290), $G \leftrightarrow C$ (sites 143 , 158,167 and 317) and $\mathrm{G} \leftrightarrow \mathrm{T}$ ( site 286). The average nucleotide composition was $40.8 \%$ adenine, $29.3 \%$ thymine, $21.8 \%$ cytosine and $8.1 \%$ guanine.

Haplotype diversity was $0.891 \pm 0.016$ (average \pm standard deviation, $\mathrm{n}=60$ ). Nucleotide diversity was $0.0109 \pm 0.0006$, with 3.702 nucleotide

Table 1

Variable sites on 17 haplotypes of ND4 mitochondrial gene of Ae. aegypti observed in Londrina, Paraná.

\begin{tabular}{|c|c|c|c|c|c|c|c|c|c|c|c|c|c|c|}
\hline \multirow{2}{*}{ Haplotype } & \multicolumn{13}{|c|}{ Nucleotide changes positions } & \multirow{2}{*}{$\mathrm{N}$} \\
\hline & 83 & 93 & 104 & 111 & 143 & 155 & 230 & 286 & 300 & 311 & 317 & 321 & 325 & \\
\hline H1 & G & A & G & $\mathrm{T}$ & G & $\mathrm{T}$ & $\mathrm{C}$ & $\mathrm{T}$ & $\mathrm{C}$ & $\mathrm{C}$ & $\mathrm{C}$ & G & G & 16 \\
\hline H2 & G & A & G & $\mathrm{T}$ & G & $\mathrm{T}$ & $\mathrm{C}$ & $\mathrm{T}$ & $\mathrm{C}$ & $\mathrm{C}$ & G & G & G & 2 \\
\hline H3 & G & A & G & $\mathrm{T}$ & G & $\mathrm{T}$ & $\mathrm{C}$ & $\mathrm{T}$ & A & G & C & G & $G$ & 2 \\
\hline H4 & G & A & $\mathrm{G}$ & $\mathrm{T}$ & $G$ & $\mathrm{~T}$ & C & $\mathrm{T}$ & C & C & C & A & G & 28 \\
\hline H5 & G & A & G & $\mathrm{T}$ & G & $\mathrm{T}$ & C & $\mathrm{T}$ & C & C & C & A & A & 52 \\
\hline H6 & G & A & G & $\mathrm{T}$ & G & G & A & $\mathrm{T}$ & C & C & C & A & A & 16 \\
\hline H7 & G & A & $\mathrm{G}$ & $\mathrm{T}$ & A & G & A & $\mathrm{T}$ & C & C & C & A & A & 2 \\
\hline H8 & $\mathrm{T}$ & $\mathrm{T}$ & G & $\mathrm{T}$ & G & $G$ & A & $\mathrm{T}$ & C & C & C & A & A & 2 \\
\hline H9 & G & A & $\mathrm{G}$ & $\mathrm{T}$ & $\mathrm{G}$ & $\mathrm{T}$ & C & $\mathrm{T}$ & C & C & C & $\mathrm{T}$ & A & 2 \\
\hline H10 & G & A & A & $\mathrm{T}$ & G & $\mathrm{T}$ & C & $\mathrm{T}$ & C & C & C & A & A & 2 \\
\hline H11 & G & A & $\mathrm{G}$ & $\mathrm{T}$ & G & $\mathrm{T}$ & C & $G$ & C & C & C & A & $\mathrm{G}$ & 47 \\
\hline H12 & G & A & $\mathrm{G}$ & $\mathrm{T}$ & G & $\mathrm{T}$ & C & $\mathrm{G}$ & C & C & C & A & A & 15 \\
\hline H13 & G & A & G & G & G & $\mathrm{T}$ & C & G & C & C & C & A & G & 8 \\
\hline H14 & G & A & G & $\mathrm{T}$ & G & $\mathrm{T}$ & C & C & C & C & C & A & G & 4 \\
\hline H15 & G & A & $\mathrm{G}$ & $\mathrm{T}$ & C & $\mathrm{T}$ & C & $G$ & C & C & C & A & $\mathrm{T}$ & 2 \\
\hline H16 & G & A & $\mathrm{G}$ & $\mathrm{T}$ & G & $\mathrm{T}$ & C & G & C & C & C & A & $\mathrm{T}$ & 2 \\
\hline H17 & G & A & G & $\mathrm{T}$ & G & $\mathrm{T}$ & C & C & C & C & C & A & $\mathrm{T}$ & 18 \\
\hline
\end{tabular}

$\mathrm{N}=$ Number of specimens that share each haplotype.

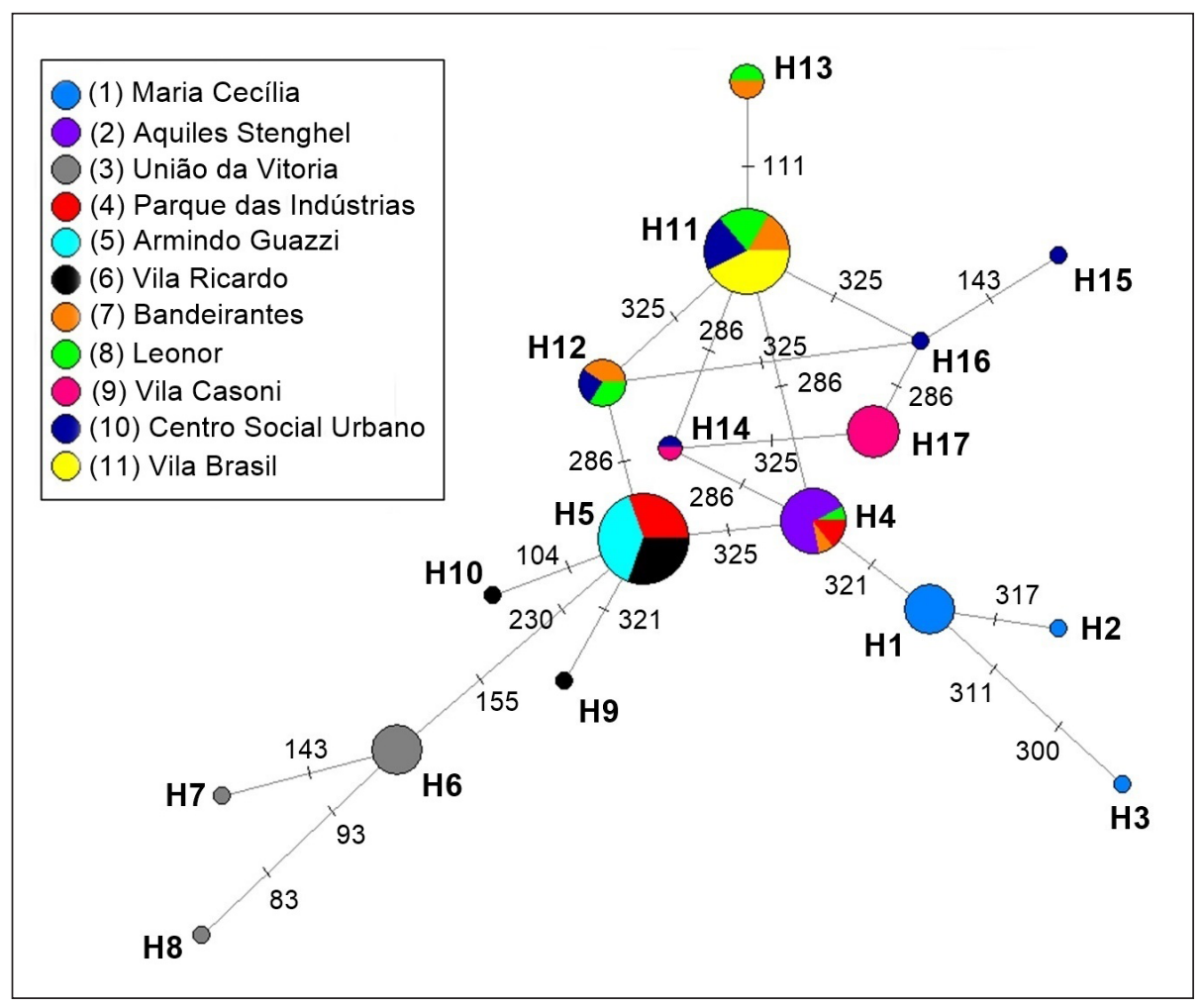

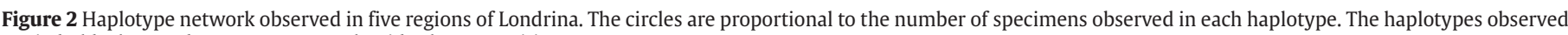
are in bold. The numbers represent nucleotide change positions. 
differences on average. Neutrality test results were not significant and were according to the model of neutral mutation ( $p>0.10$, Tajima's D 1.25761, Fu's Fs 0.897). The analysis of molecular variance (AMOVA, Fst $=0.18, \mathrm{p}<0.05)$ indicated genetic differentiation. The gene flow value was $\mathrm{Nm}=0.10$.

Evaluating the city of Londrina as a whole, 27 haplotypes were found. The analysis of molecular variance (AMOVA, Fst $=0.16, p<0.05$ ) indicated genetic differentiation. The gene flow value was $\mathrm{Nm}=0.10$ and neutrality test results were not significant and were according to the model of neutral mutation ( $p>0.10$, Tajima's D -0.74568, Fu's Fs -3.458).

\section{Val1016Ile and Phe1534Cys kdr mutations}

Regarding the evaluated specimens in Londrina's different regions, a total of 330 mosquitoes were genotyped for both mutations (30 for each location) (Fig. 4). For the Val1016Ile mutation, 30\% (98) were dominant homozygotes ( $\mathrm{Val} / \mathrm{Val}^{+}$), 40\% (133) were heterozygotes $\left(\mathrm{Val}^{+} / \mathrm{Ile} \mathrm{e}^{k r}\right.$ ) and 30\% (99) were recessive homozygotes (Ile/Ile ${ }^{k d r}$ ). The $\mathrm{Val}^{+}$allele frequency was 0.5 , and the Ile ${ }^{k d r}$ allele frequency was 0.5 for Londrina. Evaluating all populations as a group, Londrina is not balanced according to Hardy-Weinberg equilibrium for the Val1016Ile mutation (Table 3).

With the Phe1534Cys mutation, 30\% (99) were dominant homozygotes (Phe/Phe $)$, 36\% (120) heterozygotes ( $\mathrm{Phe}^{+} / \mathrm{Cys}^{k d r}$ ) and 34\% (111) recessive homozygotes (Cys/Cys ${ }^{k d r}$ ). The Phe ${ }^{+}$allele frequency was 0.45 , and the $\mathrm{Cys}^{k d r}$ frequency was 0.52 for Londrina. Evaluating all populations as a group, Londrina is not balanced according to Hardy-Weinberg for the Phe1534Cys mutation (Table 4).

On the University campus, 90 specimens were genotyped for the 1016 and 1534 fragments of $\mathrm{Na}_{\mathrm{v}}$. Regarding Val1016Ile, 17\% (15) were dominant homozygotes ( $\mathrm{Val} / \mathrm{Val}^{+}$), 52\% (47) were heterozygotes $\left(\mathrm{Val}^{+} / \mathrm{Ile}^{k d r}\right.$ ) and 31\% (28) were recessive homozygotes (Ile/Ile ${ }^{k d r}$ ). CCB, BC and CESA populations were determined according to the Hardy-Weinberg equilibrium hypothesis, and UEL's three populations were balanced (Table 5). Regarding the Phe1534Cys mutation, 11\% (10) were dominant homozygotes (Phe/Phe $)$, 53\% (48) were heterozygotes ( $\mathrm{Phe}^{+} / \mathrm{Cys}^{k d r}$ ) and $36 \%$ (32) were recessive homozygotes (Cys/Cys ${ }^{k d r}$ ). CCB, BC and CESA populations are also according to the HW equilibrium hypothesis, and all three UEL populations are balanced (Table 6).

Altogether, considering all eleven locations in Londrina and the three collection points at UEL, 420 individuals from Ae. aegypti were evaluated. Regarding the Val1016Ile mutation, 27\% (113) were dominant homozygotes $\left(\mathrm{Val} / \mathrm{Val}^{+}\right), 43 \%$ (180) were heterozygotes (Val+/Ile ${ }^{k d r}$ ) and $30 \%$ (127) were recessive homozygotes (Ile/Ile ${ }^{k d r}$ ). The $\mathrm{Val}^{+}$allele frequency was 0.52 , and the Ile ${ }^{k d r}$ allele frequency was 0.48 . Regarding the Phe1534Cys mutation, 26\% (109) were dominant homozygotes $\left(\mathrm{Phe} / \mathrm{Phe}^{+}\right.$), 40\% (168) were heterozygotes ( $\mathrm{Phe}^{+} / \mathrm{Cys}^{k d r}$ ) and 34\% (143) were recessive homozygotes (Cys/Cys ${ }^{k d r}$ ). Phe ${ }^{+}$allele frequency was 0.46 , and the Cys ${ }^{k d r}$ frequency was 0.54 . Londrina is not balanced according to HW equilibrium hypothesis for both mutations.

\section{Discussion}

Haplotypic diversity in Londrina was considered elevated $(\mathrm{Hd}=0.862)$ compared to a previous study conducted in the city, $\mathrm{Hd}=0.730$ (Twerdochlib et al., 2012), and in Foz do Iguaçu - another city in Paraná - (Hd = 0.131) (Bona et al., 2012). However, nucleotide diversity was considered low $(\pi=0.005)$ in comparison to results observed in other populations in Paraná ( $\pi=0.015$ ). For UEL's campus, haplotype diversity $(\mathrm{Hd}=0.891)$ was considered elevated in comparison to a

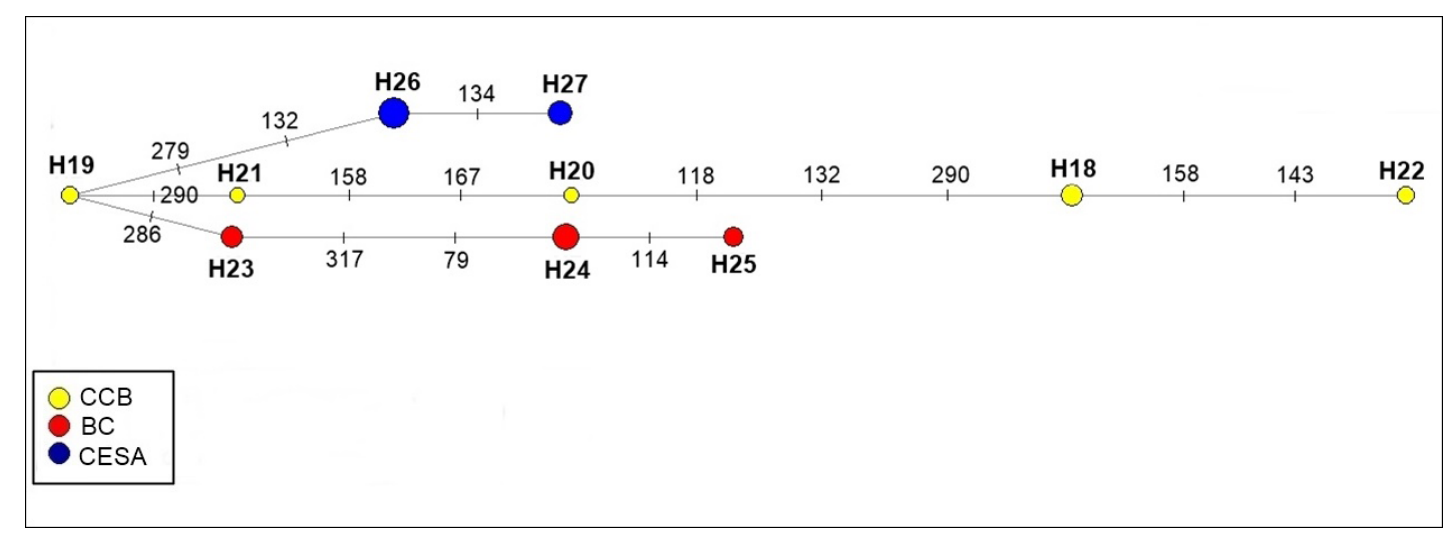

Figure 3 Haplotypic network obtained through specimens collected in UEL. The circles are proportional to the number of specimens observed in each haplotype.

Table 2

Variable sites in 10 haplotypes identified from a fragment of $339 \mathrm{pb}$ from Ae. aegypti's ND4 mitochondrial gene.

\begin{tabular}{|c|c|c|c|c|c|c|c|c|c|c|c|c|c|}
\hline \multirow{2}{*}{ Haplotype } & \multicolumn{12}{|c|}{ Nucleotide polymorphism } & \multirow{2}{*}{$\mathrm{N}$} \\
\hline & 79 & 114 & 118 & 132 & 134 & 143 & 158 & 167 & 279 & 286 & 290 & 317 & \\
\hline H18 & A & $\mathrm{T}$ & $\mathrm{C}$ & $\mathrm{C}$ & $\mathrm{C}$ & $G$ & $\mathrm{C}$ & $\mathrm{C}$ & A & $\mathrm{T}$ & A & $\mathrm{C}$ & 6 \\
\hline H19 & A & $\mathrm{T}$ & $\mathrm{T}$ & $\mathrm{T}$ & $C$ & G & G & G & A & $\mathrm{T}$ & A & C & 4 \\
\hline H2O & A & $\mathrm{T}$ & $\mathrm{T}$ & $\mathrm{T}$ & C & G & C & C & A & $\mathrm{T}$ & $\mathrm{T}$ & C & 3 \\
\hline H21 & A & $\mathrm{T}$ & $\mathrm{T}$ & $\mathrm{T}$ & $\mathrm{C}$ & G & G & G & A & $\mathrm{T}$ & $\mathrm{T}$ & $\mathrm{C}$ & 3 \\
\hline H22 & A & $\mathrm{T}$ & $\mathrm{T}$ & C & $\mathrm{C}$ & $\mathrm{C}$ & G & $\mathrm{C}$ & A & $\mathrm{T}$ & A & $\mathrm{C}$ & 4 \\
\hline H23 & A & $\mathrm{T}$ & $\mathrm{T}$ & $\mathrm{T}$ & C & G & G & G & A & G & A & C & 6 \\
\hline H24 & G & $\mathrm{T}$ & $\mathrm{T}$ & $\mathrm{T}$ & $\mathrm{C}$ & G & G & G & A & G & A & G & 9 \\
\hline H25 & G & A & $\mathrm{T}$ & $\mathrm{T}$ & C & G & G & G & A & G & A & G & 5 \\
\hline H26 & A & $\mathrm{T}$ & $\mathrm{T}$ & C & C & G & G & G & $\mathrm{T}$ & $\mathrm{T}$ & A & C & 13 \\
\hline H27 & A & $\mathrm{T}$ & $\mathrm{T}$ & C & $\mathrm{T}$ & G & G & G & $\mathrm{T}$ & $\mathrm{T}$ & A & C & 7 \\
\hline
\end{tabular}




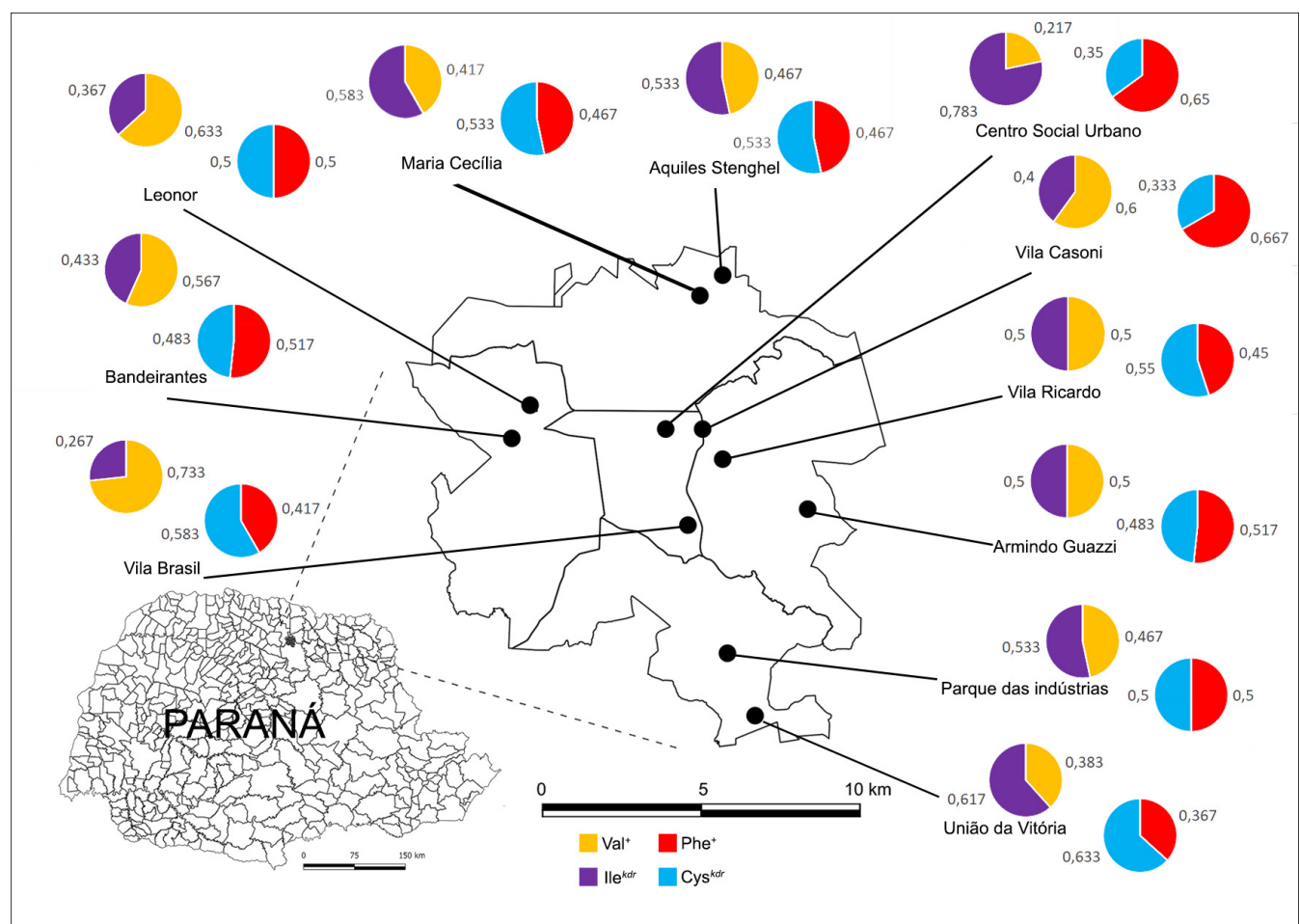

Figure 4 Allele frequencies of $\mathrm{Na}_{\mathrm{v}} \mathrm{kdr} 1016$ and 1534 genotyping distributed in the five different regions of Londrina.

Table 3

Genotypic frequency of Val1016Ile mutation of Ae. aegypti $\mathrm{Na}_{\mathrm{v}}$ for the eleven locations and Londrina as a whole. $\mathrm{X}^{2}$ values highlighted in italics show significant difference ( $>$ >0.05).

\begin{tabular}{|c|c|c|c|c|c|c|}
\hline \multirow{2}{*}{ Region } & \multirow{2}{*}{ Site } & \multirow{2}{*}{$\mathrm{N}$} & \multicolumn{3}{|c|}{ Genotypic frequency } & \multirow{2}{*}{$\mathrm{HW}^{*} \mathrm{X}^{2}$} \\
\hline & & & ${\mathrm{Val} / \mathrm{Val}{ }^{+}}$ & $\mathrm{Val}^{+} / / \mathrm{Il} \mathrm{e}^{k d r}$ & Ile/Ile ${ }^{k d r}$ & \\
\hline North & Aquiles Stenghel & 30 & 0.133 & 0.667 & 0.2 & 3.453 \\
\hline South & União da Vitória & 30 & 0.333 & 0.1 & 0.567 & 18.652 \\
\hline \multirow[t]{2}{*}{ East } & Armindo Guazzi & 30 & 0.333 & 0.333 & 0.333 & 3.333 \\
\hline & Vila Ricardo & 30 & 0.333 & 0.333 & 0.333 & 3.333 \\
\hline \multirow[t]{4}{*}{ Central } & Centro Social Urbano & 30 & 0.167 & 0.1 & 0.733 & 14.927 \\
\hline & Vila Brasil & 30 & 0.667 & 0.133 & 0.2 & 13.032 \\
\hline & Vila Casoni & 30 & 0.33 & 0.533 & 0.133 & 0.371 \\
\hline & Londrina & 330 & 0.297 & 0.403 & 0.3 & 12.411 \\
\hline
\end{tabular}

*Hardy-Weinberg equilibrium: Chi-square test with 1 degree of freedom $(\mathrm{p}>0,05)$.

Table 4

Genotypic frequency of Phe1534Cys mutation of Ae. aegypti Nav for the eleven locations and Londrina as a whole. X2 values highlighted in italics show significant difference $(\mathrm{p}>0.05)$.

\begin{tabular}{|c|c|c|c|c|c|c|}
\hline \multirow{2}{*}{ Region } & \multirow{2}{*}{ Site } & \multirow{2}{*}{$\mathrm{N}$} & \multicolumn{3}{|c|}{ Genotypic frequency } & \multirow{2}{*}{$\mathrm{HW}^{*} \mathrm{X}^{2}$} \\
\hline & & & $\mathrm{Phe} \mathrm{Phe}^{+}$ & $\mathrm{Phe}^{+} / \mathrm{Cys}^{k d r}$ & Cys/Cys ${ }^{k d r}$ & \\
\hline \multirow[t]{2}{*}{ North } & Maria Cecília & 30 & 0,2 & 0.533 & 0.267 & 0.153 \\
\hline & Aquiles Stenghel & 30 & 0,1 & 0.733 & 0.167 & 6.718 \\
\hline \multirow[t]{2}{*}{ South } & Parque das Indústrias & 30 & 0.267 & 0.2 & 0.533 & 9.726 \\
\hline & União da Vitória & 30 & 0.333 & 0.333 & 0.333 & 3.333 \\
\hline \multirow[t]{2}{*}{ East } & Armindo Guazzi & 30 & 0.367 & 0.3 & 0.333 & 4.783 \\
\hline & Vila Ricardo & 30 & 0.334 & 0.233 & 0.333 & 8.383 \\
\hline \multirow[t]{2}{*}{ West } & Leonor & 30 & 0.167 & 0.666 & 0.167 & 3.333 \\
\hline & Bandeirantes & 30 & 0.267 & 0.5 & 0.233 & - \\
\hline \multirow[t]{4}{*}{ Central } & Centro Social Urbano & 30 & 0.433 & 0 & 0.567 & 30 \\
\hline & Vila Brasil & 30 & 0.167 & 0.5 & 0.333 & 0.024 \\
\hline & Vila Casoni & 30 & 0.667 & 0 & 0.333 & 30 \\
\hline & Londrina & 330 & 0.3 & 0.363 & 0.337 & 24.372 \\
\hline
\end{tabular}

${ }^{*}$ Hardy-Weinberg equilibrium: Chi-square test with 1 degree of freedom $(p>0,05)$. 
Table 5

Genotypic frequency of Val1016Ile mutation of Ae. aegypti $\mathrm{Na}_{\mathrm{v}}$ of three sites in UEL, both individually and as a whole.

\begin{tabular}{|c|c|c|c|c|c|c|c|}
\hline \multirow{2}{*}{ Site } & \multirow{2}{*}{$\mathrm{N}$} & \multicolumn{3}{|c|}{ Genotypic frequency } & \multicolumn{2}{|c|}{ Allele frequency } & \multirow{2}{*}{$\mathrm{HW}^{*} \mathrm{X}^{2}$} \\
\hline & & $\mathrm{Val} / \mathrm{Val}^{+}$ & $\mathrm{Val}^{+} / \mathrm{Ile}^{k d r}$ & Ile/Ile $\mathrm{Idr}^{k d r}$ & Val & Ile & \\
\hline Centro de Ciências Biológicas & 30 & 0.1 & 0.6 & 0,3 & 0.4 & 0.6 & 1.875 \\
\hline Biblioteca Central & 30 & 0.3 & 0.367 & 0.333 & 0.48 & 0.51 & 2.12 \\
\hline Centro de Estudos Sociais Aplicados & 30 & 0.1 & 0.6 & 0.3 & 0.4 & 0.6 & 1.875 \\
\hline UEL & 90 & 0.167 & 0.522 & 0.311 & 0.427 & 0.573 & 0.4 \\
\hline
\end{tabular}

${ }^{*}$ Hardy-Weinberg equilibrium: Chi-square test with 1 degree of freedom ( $\left.p>0,05\right)$.

Table 6

Genotypic frequency of Phe1534Cys mutation of Ae. aegypti $\mathrm{Na}_{\mathrm{v}}$ of three sites in UEL, both individually and as a whole.

\begin{tabular}{|c|c|c|c|c|c|c|c|}
\hline \multirow{2}{*}{ Site } & \multirow{2}{*}{$\mathrm{N}$} & \multicolumn{3}{|c|}{ Genotypic frequency } & \multicolumn{2}{|c|}{ Allele frequency } & \multirow{2}{*}{$\mathrm{HW}^{*} \mathrm{X}^{2}$} \\
\hline & & Phe/Phe ${ }^{+}$ & $\mathrm{Phe}^{+} / \mathrm{Cys}^{k d r}$ & Cys/Cys ${ }^{k d r}$ & Phe & Cys & \\
\hline Centro de Ciências Biológicas & 30 & 0.067 & 0.533 & 0,4 & 0.333 & 0.667 & 1.2 \\
\hline Biblioteca Central & 30 & 0.2 & 0.5 & 0.3 & 0.45 & 0.55 & 0.003 \\
\hline Centro de Estudos Sociais Aplicados & 30 & 0.067 & 0.567 & 0.366 & 0.35 & 0.65 & 1.807 \\
\hline UEL & 90 & 0.111 & 0.533 & 0.356 & 0.378 & 0.622 & 1.627 \\
\hline
\end{tabular}

${ }^{*}$ Hardy-Weinberg equilibrium: Chi-square test with 1 degree of freedom $(p>0,05)$.

previous study in Londrina ( $\mathrm{Hd}=0.730$ ) (Twerdochlib et al., 2012) and very similar to the diversity obtained to the city in the present study. Genetic diversity was quite similar $(\pi=0.010)$ in comparison to other populations of Paraná $(\pi=0.015)$ and larger than that observed in the present study in the city of Londrina.

None of the polymorphic sites coincide with those observed by Twerdochlib et al. (2012). However, changes in positions 143, 186 and 317 were also observed in the present study's analysis. Taking UEL into consideration, each site's haplotype exclusivity became evident: $\mathrm{H} 19-\mathrm{H} 22$ for CCB, H23-H25 for BC and H26-H27 for CESA (Fig. 3). Although the geographic distance among the locations is rather short, the stress in each of them is different, matching the obtained results.

Each studied center's peculiarities must be taken into consideration. CCB is in one of the edges of the campus, close to the highway, and a place of heavy movement of people, including the external community since it holds the University Clinical Hospital. Biblioteca Central is in the campus' central region, near the University Restaurant. In both places, the movement of people is intense, since it is frequented by a large portion of the campus community. CESA is on the other edge of the campus, near the University Garden, a more vegetated and conserved location.

The analysis of molecular variance indicated high genetic differentiation both in Londrina and in UEL. This AMOVA result, together with the peculiarities of each location, especially at the UEL, where the collection points are more different from each other, shows that there may be different types of stress in each location (Fig 1). The low gene flow value also reaffirms this possibility, since it shows that inter-population transfer of the gene is more restricted, in addition to the mosquito's reduced biologic dispersion characteristic (Honório et al., 2003).

Chemical measures used in vector control programs affect the genetic diversity of Ae. aegypti populations and, as a result, may induce genetic alterations through population bottleneck and genetic drift (Urdaneta-Marquez and Failloux, 2011). In South America - in countries such as Brazil, Argentina, French Guiana, Colombia, Peru and Venezuela - successive control programs implemented over the last years to fight Ae. aegypti and control dengue and other arboviruses caused demographic effects that led to intense gene drift and an elevated level of gene differentiation at both continental and local scales (UrdanetaMarquez and Failloux, 2011; Paupy et al., 2012). In addition, such drift effects might be explained due to the vector mosquito's own biologic characteristic: females perform a weak dispersion, which does not surpass a few hundred meters during their lifetime, stablishing themselves in restricted regions (Honório et al., 2003; Urdaneta-Marquez and Failloux, 2011). Long-distance mosquito dispersion only occurs passively (eggs and adults transported in cars and public transportation; egg recipients transported to different locations), which might explain the coexistence of some haplotypes in different locations observed in Londrina.

The high frequencies of mutant alleles observed in a large part of the evaluated populations are alarming, as the polymorphisms tend to increase their frequency should the selection pressure be constant, eventually reaching fixation (Martins and Valle, 2012). In the present study, considering all collection sites in Londrina, the $k d r$ resistance alleles were present in 50\% of the Val1016Ile mutation and $48 \%$ of the Phe1534Cys mutation. Although the dominant allele presents higher frequency than the recessive mutant in some locations - such as sites 8, 9 and 11 for the Val1016Ile mutation and 5, 7, 9 and 10 for Phe1534 - it is important to point out that heterozygosity must be taken into consideration. The western region, for instance, presented a high frequency of the heterozygote genotype for both mutations (Tables 3 and 4), which despite not having the resistance phenotype, carries the resistant allele that may be transferred to mosquitoes over generations.

For some of the locations, the allele frequency is equivalent: at sites 5 and 6 for the Val1016lle mutation and at sites 4 and 8 for the Phe1534Cys mutation. The particularity of some locations cannot be overlooked: at site 10 (Centro Social Urbano), there is a higher frequency of the Ile ${ }^{k d r}$ allele than the Val ${ }^{+}$allele, whereas Cys ${ }^{k d r}$ allele's frequency is lower than the Phe'. At site 11 (Vila Brasil), the opposite occurs: the $\mathrm{Val}^{+}$allele is more frequent than the Ile ${ }^{k d r}$ allele, while the Cys ${ }^{k d r}$ allele's frequency is higher than that of $\mathrm{Phe}^{+}$.

The Hardy-Weinberg equilibrium hypothesis describes the influence of random reproduction in allele and genotypical frequencies on an infinitely large population. Although in almost all populations from different locations in Londrina the allelic frequencies were according to HW, when we group different populations in a large population per geographic region - or even the city as a whole - we are able to see HW deviations with Wahlund's effect (Wahlund, 1928). This shows that the populations were isolated from each other, and the $k d r$ occurrence seems to be an independent effect, likely reflecting the chosen insecticide strategy for each part of the city.

In UEL and Londrina, the presence of recessive resistance alleles 1016Ile and 1534 Cys was more frequent in almost all populations (except Vila 


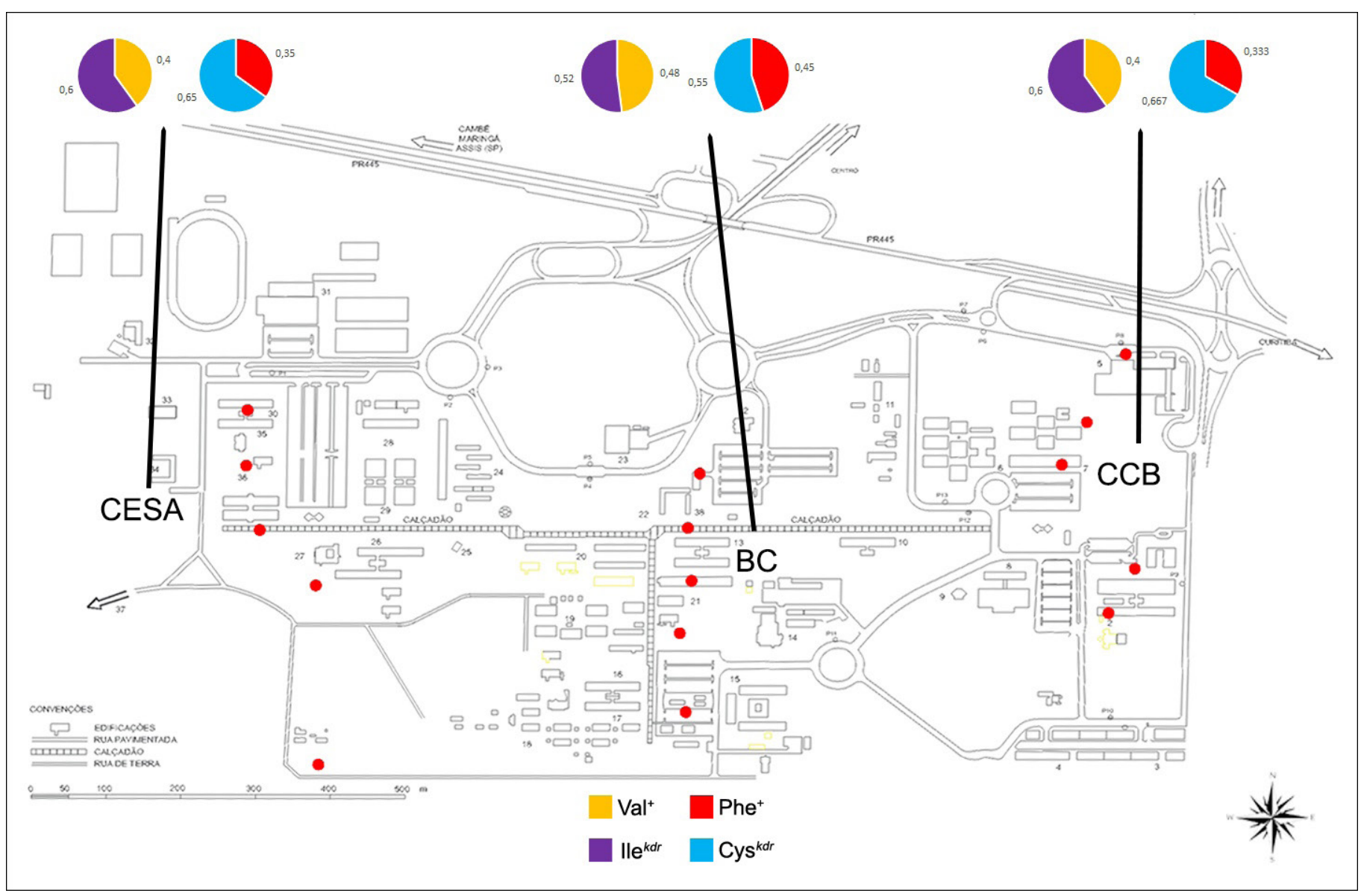

Figure $5 \mathrm{Na}_{\mathrm{v}} k d r 1016$ and 1534 site allele frequencies in UEL. Collection site locations were distributed in the three regions of the campus.

Casoni, Vila Brasil and Bandeirantes for both alleles and Vila Brasil for allele 1016Ile) (Tables 5 and 6, Figs. 4 and 5). The Phe1534Cys mutation has been provenly related to PY resistance (Saavedra-Rodriguez et al., 2018), which makes the obtained results alarming. The high frequency of the heterozygote genotypes $\mathrm{Val}^{+} / \mathrm{Ile}^{k d r}$ and $\mathrm{Phe}^{+} / \mathrm{Cys}^{k d r}$ in all locations is also worrying, since although both genotypes do not confer the resistance phenotype, they carry the resistance allele that might be transferred by mosquitoes over generations. In the case of constant pressure, such alleles might reach fixation (Martins et al., 2009).

Our data show that PY insecticide application in the campus, as well as the rest of the city, would probably not be able to control Ae. aegypti, and new strategies should be put in motion. However, it is only possible to carry out the control if it is combined with monitoring policies. An alternative monitoring method of Ae. aegyptiis the detection and quantification of eggs deposited in oviposition traps installed in the home environment, which allows the identification of areas with the presence mosquito and the analysis of the spatial and temporal distribution of its population (Degener et al., 2014). Oviposition traps are a cheap and sensitive tool for the detection of Ae. aegypti in the environment. Its use is especially important to guide the control of Ae. aegypti, perform vector control actions, and reduce mosquito infestation. Potentially, there is a reduction in the risk of transmission of the Dengue virus, resulting in a lower incidence of cases. In Colombia, oviposition traps were a useful tool in vector surveillance, as well as vector control, mainly when used as part of the integrated vector control approach (Alarcón et al., 2014).

The association of different control methods, as oviposition combined with genetic information, can be an important in the process of surveillance of the Ae. aegypti. This methodologies can provide significant information about the mosquito's oviposition in that location, its genetic variability and mutations, and to improve current control strategies. The elimination of mosquito breeding sites is still considered to be a more effective control strategy and intensify this monitoring may be the cheapest and most advantageous way to control this vector of arboviruses.

\section{Conclusions}

Our results showed that the populations of Ae. aegypti tend to be structured and genetically distinct with low gene flux. As $\mathrm{Na}_{\mathrm{v}}$, the ND4 gene might be under the influence of synthetic products since the chemical actions used in Ae. aegypticontrol programs affect mosquito populations' genetic diversity. Populations might have different responses when PY control actions occur, increasing the complexity of effective control. This highlights the need of a stricter government action in the inspection and monitoring of Ae. aegypti in urban areas, as well as the regulation or control in domestic use of pyrethroids. In addition, it is important to educate the population to act in eliminating mosquito breeding sites, preventing its proliferation, and the increase of arboviruses.

\section{Acknowledgements}

The authors are grateful to the Secretaria Municipal de Saúde de Londrina (Londrina Municipal Health Secretary) for authorizing this 
project. The authors declare that they have no conflicts of interest. All applicable international, national, and/or institutional guidelines for the care and use of animals were followed.

\section{Funding}

This work was supported by Universidade Estadual de Londrina, Conselho Nacional de Desenvolvimento Científico e Tecnológico (CNPq) [grant number 440385/2016-4] and financed in part by the Coordenação de Aperfeiçoamento de Pessoal de Nível Superior - Brasil (CAPES) [Finance Code 001].

\section{Data statement}

The haplotypes reported in this paper have been deposited in GenBank and are available under access numbers MN385630-MN385656.

\section{Conflicts of interest}

The authors declare they have no conflicts of interest.

\section{Compliance with ethical standards}

Not applicable.

\section{Author contribution statement}

TBFL, JACZ, MANS and RdR Conceived and designed the experiments. TBFL, BVB, BPS and TRA Performed the experiments. TBFL, GLTVB and RdR Analyzed the data. JACZ, MANS and RdR Contributed reagents/ materials/analysis tools. TBFL and RdR Wrote the paper. All authors read and approved the final version of the manuscript.

\section{References}

Aguirre-Obando, O. A., Bona, A. C. D., Duque L, J. E., Navarro-Silva, M. A., 2015. Insecticide resistance and genetic variability in natural populations of Aedes (Stegomyia) aegypti (Diptera: Culicidae) from Colombia. Zoologia 32 (1), 14-22. http://dx.doi.org/10.1590/ S1984-46702015000100003.

Alarcón, E. P., Segura, A. M., Uribe, G. R., 2014. Evaluation of oviposition traps for surveillance and control of Aedes aegypti in two urban centers of the Antioquia Urabá. Biomedica 34 (3), 404-424.

Araújo, H., Carvalho, D., Ioshino, R., Costa-da-Silva, A., Capurro, M., 2015. Aedes aegypti control strategies in Brazil: incorporation of new technologies to overcome the persistence of dengue epidemics. Insects 6 (2), 576-594. http://dx.doi.org/10.3390/insects6020576.

Bandelt, H., Forster, P., Rohl, A., 1999. Median-joining networks for inferring intraspecific phylogenies. Mol. Biol. Evol. 16 (1), 37-48. http://dx.doi.org/10.1093/oxfordjournals.molbev.a026036.

Bona, A., Piccoli, C., Leandro, A., Kafka, R., Twerdochilib, A., NavarroSilva, M., 2012. Genetic profile and molecular resistance of Aedes (Stegomyia) aegypti (Diptera: Culicidae) in Foz do Iguaçu (Brazil) at the border with Argentina and Paraguay. Zoologia 29 (6), 540-548. http://dx.doi.org/10.1590/S1984-46702012000600005.

Bracco, J., Capurro, M., Lourenço-de-Oliveira, R., Sallum, M., 2007. Genetic variability of Aedes aegypti in the Americas using a mitochondrial gene: evidence of multiple introductions. Mem.
Inst. Oswaldo Cruz 102 (5), 573-580. http://dx.doi.org/10.1590/ S0074-02762007005000062.

Braga, I., Valle, D., 2007. Aedes aegypti: resistance, surveillance and monitoring, and control alternatives in Brazil. Epidemiol. Serv. Saude 16 (4), 295-302. https://doi.org/10.5123/S1679-49742007000400007.

Catterall, W., 2000. Structure and Regulation of Voltage-Gated Ca2+Channels. Annu. Rev. Cell Dev. Biol. 16 (1), 521-555. http:// dx.doi.org/10.1146/annurev.cellbio.16.1.521.

Consoli, R., Oliveira, R., 1994. Main Mosquitos of Sanitary Importance in Brazil, 1st ed. Editora Friocruz, Rio de Janeiro. Available in: https:// www.arca.fiocruz.br/handle/icict/2708 (accessed 20 July 2020).

Costa-da-Silva, A., Capurro, M., Bracco, J., 2005. Genetic lineages in the yellow fever mosquito Aedes (Stegomyia) aegypti (Diptera: Culicidae) from Peru. Mem. Inst. Oswaldo Cruz 100 (6), 539-544. http://dx.doi.org/10.1590/S0074-02762005000600007.

Da-Cunha, M., Lima, J., Brogdon, W., Moya, G., Valle, D., 2005. Monitoring of resistance to the pyrethroid cypermethrin in Brazilian Aedes aegypti (Diptera: Culicidae) populations collected between 2001 and 2003. Mem. Inst. Oswaldo Cruz 100 (4), 441-444. http://dx.doi. org/10.1590/S0074-02762005000400017.

Degener, C. M., Ázara, T. M. F. D., Roque, R. A., Codeço, C. T., Nobre, A. A., Ohly, J. J., Geier, M., Eiras, Á. E., 2014. Temporal abundance of Aedes aegypti in Manaus, Brazil, measured by two trap types for adult mosquitoes. Mem. Inst. Oswaldo Cruz 109 (8), 1030-1040. http://dx.doi.org/10.1590/0074-0276140234.

Depoli, P., Zequi, J., Nascimento, K., Lopes, J., 2016. Eficácia de ovitrampas com diferentes atrativos na vigilância e controle de Aedes. EntomoBrasilis 9 (1), 51-55. http://dx.doi.org/10.12741/ ebrasilis.v9i1.509.

Excoffier, L., Lischer, H., 2010. Arlequin suite ver 3.5: a new series of programs to perform population genetics analyses under Linux and Windows. Mol. Ecol. Resour. 10 (3), 564-567. http://dx.doi. org/10.1111/j.1755-0998.2010.02847.x.

Forattini, O., 2002. Culicidologia médica: identificação, biologia e epidemiologia, 2nd ed. Edusp, São Paulo.

Hall, T., 2005. Bioedit v 7.0.5. Ibis Therapeutics, a division of Isis Pharmaceuticals, Carlsbad.

Harris, A., Ranson, H., Rajatileka, S., 2010. Pyrethroid Resistance in Aedes aegypti from Grand Cayman. Am. J. Trop. Med. Hyg. 83 (2), 277-284. http://dx.doi.org/10.4269/ajtmh.2010.09-0623.

Honório, N., Silva, W., Leite, P., Gonçalves, J., Lounibos, L., Lourenço-deOliveira, R., 2003. Dispersal of Aedes aegypti and Aedes albopictus (Diptera: Culicidae) in an urban endemic dengue area in the State of Rio de Janeiro, Brazil. Mem. Inst. Oswaldo Cruz 98 (2), 191-198. http://dx.doi.org/10.1590/S0074-02762003000200005.

Lima Júnior, R., Scarpassa, V., 2009. Evidence of two lineages of the dengue vector Aedes aegypti in the Brazilian Amazon based on mitochondrial DNA ND4 gene sequences. Genet. Mol. Biol. 32 (2), 414-422. http://dx.doi.org/10.1590/S1415-47572009005000036.

Lima, E., Paiva, M., Araújo, A., Silva, E., Silva, U., Oliveira, L., Wilding, C., 2011. Insecticide resistance in Aedes aegypti populations from Ceará, Brazil. Parasit. Vectors 4(1), 5. http://dx.doi.org/10.1186/17563305-4-5.

Lima, J., Silva Soares, S., Valle, D., Ramos, R., Ribeiro Galardo, A., DaCunha, M. P., Braga, I. A., Silva Júnior, R. C., 2003. Resistance of Aedes aegypti to organophosphates in several municipalities in the state of Rio de Janeiro and Espirito Santo, Brazil. Am. J. Trop. Med. Hyg. 68 (3), 329-333. http://dx.doi.org/10.4269/ajtmh.2003.68.329.

Linss, J., Brito, L., Garcia, G., Araki, A., Bruno, R., Lima, J., Valle, D., Martins, A., 2014. Distribution and dissemination of the Val1016lle and Phe1534Cys Kdr mutations in Aedes aegypti Brazilian natural 
populations. Parasit. Vectors 7 (1), 25. http://dx.doi.org/10.1186/17563305-7-25.

Martins, A., Belinato, T., Lima, J., Valle, D., 2008. Chitin synthesis inhibitor effect on Aedes aegypti populations susceptible and resistant to organophosphate temephos. Pest Manag. Sci. 64 (6), 676-680. http://dx.doi.org/10.1002/ps.1547.

Martins, A., Lima, J., Peixoto, A., Valle, D., 2009. Frequency of the Val1016Ile mutation in the voltage-gated sodium channel gene of Aedes aegypti Brazilian populations. Trop. Med. Int. Health 14 (11), 1351-1355. http://dx.doi.org/10.1111/j.1365-3156.2009.02378.x.

Martins, A., Valle, D., 2012. The pyrethroid knockdown resistance. In: Soloneski, S., Larramendy, M.L. (Eds.), Insecticides: Basic and Other Applications. IntechOpen, London. Available in: http://cdn. intechopen. com/pdfs/27797/InTech-The_pyrethroid_knockdown_resistance. pdf (accessed 19 January 2019).

Ministério da Saúde, 2020. Boletim epidemiológico. Vol. 1. Available in: https://www.saude.gov.br/images/pdf/2020/janeiro/20/Boletimepidemiologico-SVS-02-1-.pdf (accessed 20 July 2020).

Paupy, C., Le Goff, G., Brengues, C., Guerra, M., Revollo, J., Barja Simon, Z., Hervé, J.-P., Fontenille, D., 2012. Genetic structure and phylogeography of Aedes aegypti, the dengue and yellow-fever mosquito vector in Bolivia. Infect. Genet. Evol. 12 (6), 1260-1269. http://dx.doi. org/10.1016/j.meegid.2012.04.012.

Rozas, J., Ferrer-Mata, A., Sánchez-DelBarrio, J., Guirao-Rico, S., Librado, P., Ramos-Onsins, S., Sánchez-Gracia, A., 2017. DnaSP 6: DNA sequence polymorphism analysis of large data sets. Mol. Biol. Evol. 34 (12), 3299-3302. http://dx.doi.org/10.1093/molbev/msx248.

Saavedra-Rodriguez, K., Maloof, F., Campbell, C., Garcia-Rejon, J., Lenhart, A., Penilla, P., Rodriguez, A., Sandoval, A. A., Flores, A. E., Ponce, G., Lozano, S., Black 4th, W. C., 2018. Parallel evolution of vgsc mutations at domains IS6, IIS6 and IIIS6 in pyrethroid-resistant Aedes aegypti from Mexico. Sci. Rep. 8 (1), 6747. http://dx.doi. org/10.1038/s41598-018-25222-0.

Saavedra-Rodriguez, K., Urdaneta-Marquez, L., Rajatileka, S., Moulton, M., Flores, A., Fernandez-Salas, I., Bisset, J., Rodriguez, M., Mccall, P. J., Donnelly, M. J., Ranson, H., Hemingway, J., Black 4th, W. C., 2007. A mutation in the voltage-gated sodium channel gene associated with pyrethroid resistance in Latin American Aedes aegypti. Insect Mol. Biol. 16 (6), 785-798. http://dx.doi.org/10.1111/j.13652583.2007.00774.x.

Thompson, J., Higgins, D., Gibson, T., 1994. Clustal W: improving the sensitivity of progressive multiple sequence alignment through sequence weighting, position-specific gap penalties and weight matrix choice. Nucleic Acids Res. 22 (22), 4673-4680. http://dx.doi. org/10.1093/nar/22.22.4673.

Twerdochlib, A., Bonna, A., Leite, S., Chitolina, R., Westphal, B., NavarroSilva, M., 2012. Genetic variability of a population of Aedes aegypti from Paraná, Brazil, using the mitochondrial ND4 gene. Rev. Bras. Entomol. 56 (2), 249-256. http://dx.doi.org/10.1590/S008556262012005000030.

Urdaneta-Marquez, L., Failloux, A., 2011. Population genetic structure of Aedes aegypti, the principal vector of dengue viruses. Infect. Genet. Evol. 11 (2), 253-261. http://dx.doi.org/10.1016/j.meegid.2010.11.020.

Vontas, J., Kioulos, E., Pavlidi, N., Morou, E., della Torre, A., Ranson, H., 2012. Insecticide resistance in the major dengue vectors Aedes albopictus and Aedes aegypti. Pestic. Biochem. Physiol. 104 (2), 126-131. http://dx.doi.org/10.1016/j.pestbp.2012.05.008.

Wahlund, S., 1928. Zusammensetzung von Population und Korrelationserscheinung vom Standpunkt der Vererbungslehre aus betrachtet. Hereditas 11 (1), 65-106. http://dx.doi. org/10.1111/j.1601-5223.1928.tb02483.x.

Walter Reed Biosystematics Unit - WRBU, 2018. Medically Important Arthropods Keys. Available in: http://www.wrbu.org/aors/ southcom_Keys.html (accessed 23 July 2018).

World Health Organization - WHO, 2018. Dengue and Severe Dengue. Available in: https://www.who.int/news-room/fact-sheets/detail/ dengue-and-severe-dengue (accessed 7 July 2018).

Wright, S., 1921. Systems of mating. I. The biometric relations between parent and offspring. Genetics 6 (2), 111-123. http://dx.doi. org/10.1093/genetics/6.2.111.

Zara, A., Santos, S., Fernandes-Oliveira, E., Carvalho, R., Coelho, G., 2016. Aedes aegypticontrol strategies: a review. Epidemiol. Serv. Saude 25 (2), 391-404. https://doi.org/10.5123/s1679-49742016000200017. 


\section{Supplementary material}

The following online material is available for this article:

Table S1 - Location, number of specimens (N) and geographic coordinates of each collection site. 